\title{
Hydrogen Adsorption of PAN-based Porous Carbon Nanofibers using MgO as the Substrate
}

\author{
Min-Jung Jung ${ }^{1}$, Ji Sun Im¹, Euigyung Jeong, Hangkyo Jin² and Young-Seak Lee,^ \\ ${ }^{1}$ Dept. of Applied Chemistry and Biological Engineering, Chungnam National University, Daejeon 305-764, Korea \\ ${ }^{2}$ Korea Research Institute of Chemical Technology, P.O. Box 107, Yuseong, Daejeon 305-600, Korea \\ ‘e-mail: youngslee@cnu.ac.kr \\ (Received June 30, 2009; Accepted August 13, 2009)
}

\begin{abstract}
In this study, porous electrospun carbon fibers were prepared by electrospinning with $\mathrm{PAN}$ and $\mathrm{MgCl}_{2}$, as a $\mathrm{MgO}$ precursor. $\mathrm{MgO}$ was selected as a substrate because of its chemical and thermal stability, no reaction with carbon, and ease of removal after carbonization by dissolving out in acidic solutions. $\mathrm{MgCl}_{2}$ was mixed with polyacrylonitrile (PAN) solution as a precursor of $\mathrm{MgO}$ with various weight ratios of $\mathrm{MgCl}_{2} / \mathrm{PAN}$. The average diameter of porous electrospun carbon fibers increased from 1.3 to $3 \mu \mathrm{m}$, as the $\mathrm{MgCl}_{2}$ to PAN weight ratio increased. During the stabilization step, $\mathrm{MgCl}_{2}$ was hydrolyzed to $\mathrm{MgOHCl}$ by heat treatment. At elevated temperature of $823 \mathrm{~K}$ for carbonization step, $\mathrm{MgOHCl}$ was decomposed to $\mathrm{MgO}$. Specific surface area and pore structure of prepared electrospun carbon fibers were decided by weight ratio of $\mathrm{MgCl}_{2} / \mathrm{PAN}$. The amount of hydrogen storage increased with increase of specific surface area and micropore volume of prepared electrospun carbon fibers.
\end{abstract}

Keywords : Electrospinning, Porous carbon material, Carbon nanofiber, Physical activation

\section{Introduction}

Diversity of porous carbon materials produced so far is remarkable, due to their variety of applications, such as adsorbents, catalytic supports, and etc. [1] and activated carbons are one of the important materials for porous carbon materials. Activated carbons can be produced from various carbonaceous materials. Polymer precursors are especially preferred when carbon with low inorganic impurities is needed. The most well studied polymer is PAN (polyacrylonitrile). PAN-based activated carbons have drawn increasing attention because of their excellent surface properties and adsorption capacity [2].

Porous carbon fibers with smaller fiber diameter have advantages, such as narrower pore size distribution and better adsorption capacity at low concentration of adsorbates compared than conventional activated carbons [3]. The preparation of porous carbon materials needs one more step activation of carbon materials with $\mathrm{KOH}[4,5], \mathrm{NaOH}[6,7]$ or oxidizing gas [8]. However, there have been reported various precursors and processes to prepare porous carbons without any activation process. Porous carbons were prepared by using various templates, such as zeolites and silicas [9-11]. The template had to be dissolved out by strong acids after carbonization, so its mass production was not easy. A simple process was developed to prepare porous carbon materials from PVA (polyvinyl alcohol) or PVC (polyvinyl chloride) using $\mathrm{MgO}$ as the substrate [12,13]. $\mathrm{MgO}$ was selected as a substrate because of its chemical and thermal stability, no structural and compositional changes, no reaction with carbon, and convenience of dissolving out in acidic solutions [14]. In this experiment, $\mathrm{MgCl}_{2}$ was newly used to prepare porous carbon fibers as a $\mathrm{MgO}$ precursor, because using $\mathrm{MgCl}_{2}$ as a $\mathrm{MgO}$ precursor was easier to control pore size distribution than using $\mathrm{MgO}$ directly [14]. This suggested a new preparation process of porous carbons without activation processes.

Therefore, in this study, porous electrospun carbon fibers were prepared to apply as a hydrogen carrier by electrospinning with a PAN and $\mathrm{MgCl}_{2}$ solution. The capacity of hydrogen storage was compared by using these electrospun fibers based on the investigation of their pore structure and shape.

\section{Experimental}

\subsection{Materials and Sample Preparation}

As a $\mathrm{MgO}$ precursors, $\mathrm{MgCl}_{2}$ (magnesium chloride anhydrous, Junsei, assay: 97.0\%) was used and PAN (polyacrylonitrile, Aldrich) was used as a carbon precursor. PAN was dissolved in DMF (N,N-dimethyl formamide, Acros) at $353 \mathrm{~K}$, with $10 \mathrm{wt} \%$ concentration. $\mathrm{MgCl}_{2}$ was added to the $\mathrm{PAN}$ solution with various mixing ratios of $\mathrm{MgCl}_{2} / \mathrm{PAN} ; 1 / 3,2 / 3$, and 3/3, respectively. And the mixed solution was used for electrospinning (voltage: $17 \mathrm{kV}$, syringe rate: $1.5 \mathrm{cc} / \mathrm{h}$ ). Then, electrospun fibers were stabilized at a temperature of $523 \mathrm{~K}$ for $8 \mathrm{hr}$ in air. Stabilized fibers were 


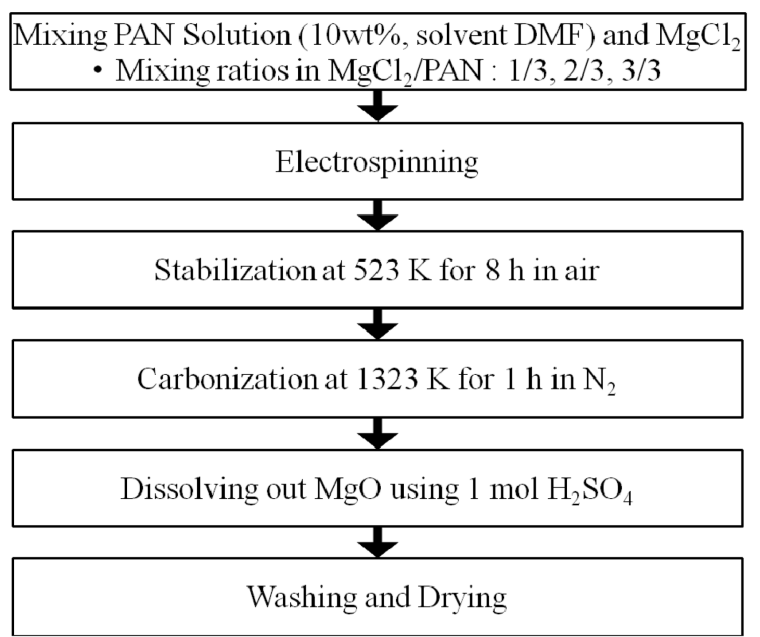

Fig. 1. The schematic diagram of procedure for PAN-based porous carbon nanofibers.

heated at $1323 \mathrm{~K}$ for $1 \mathrm{hr}$ under nitrogen atmosphere for carbonization. After carbonization, the substrate $\mathrm{MgO}$ was dissolved out of electrospun fibers with $1 \mathrm{~mol} / \mathrm{L} \mathrm{H}_{2} \mathrm{SO}_{4}$. The schematic diagram of this procedure is illustrated in Fig. 1. The final electrospun fiber products were called EM1, EM2, and $\mathrm{EM} 3$, based on the mixing ratios of $\mathrm{MgCl}_{2} / \mathrm{PAN}$.

\subsection{Characterization}

The morphologies of samples were observed with Scanning Electron Microscope (SEM, JSM-6300, JEOL LTD, Japan). The Samples were subjected to X-ray diffraction (XRD, Model D/MAX-2200 Ultima/PC, CuKa Rigaku, Japan) and thermo gravimetric analysis (TGA, Mettler-Toledo, TGA/ SDTA851, Switzerland) in $\mathrm{N}_{2}$ from room temperature to $1073 \mathrm{~K}$, with heating rate of $10 \mathrm{~K} / \mathrm{min}$. And Pore structure of carbons was assessed by $\mathrm{N}_{2}$ adsorption with weight ratio of $\mathrm{MgCl}_{2}$. To test hydrogen adsorption capacities, samples were degassed at $473 \mathrm{~K}$ for $2 \mathrm{hr}$ and hydrogen adsorption was conducted at $303 \mathrm{~K}$ from 0 to $50 \mathrm{~atm}$ by using volumetric method with PCT apparatus (Mirae SI Co., Korea).

\section{Results and Discussion}

Fig. 2 shows the morphologies of porous electrospun carbon fibers prepared in this study. Average diameter of porous electrospun carbon fibers increases from 1.3 to $3 \mu \mathrm{m}$ with increasing the amount of $\mathrm{MgCl}_{2}$ added in polymer solution. It is believed that surface tensions, viscosities, and conductivities of polymer solution are changed with the polymer solution composition change [3], and those changes of polymer solution also increase or decrease average diameter of electrospun fibers.

Fig. 3 presents the XRD spectra of $\mathrm{MgCl}_{2}$ in electrospun carbon fibers at each preparation step. Other work by the
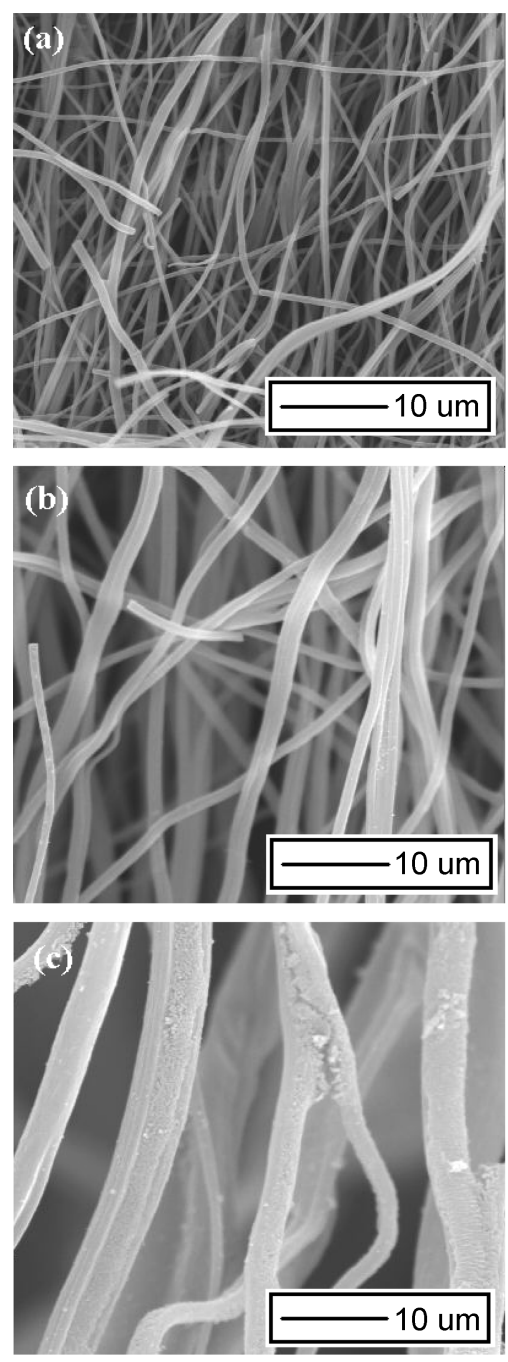

Fig. 2. SEM images of porous electrospun carbon fibers various mixing ratios in $\mathrm{MgCl}_{2} / \mathrm{PAN}$ : (a) $1 / 3$; (b) $2 / 3$ and (c) $3 / 3$.

authors [15-17] describes the procedure to produce $\mathrm{MgOHCl}$ from chemical grade $\mathrm{MgCl}_{2}$. This is in good agreement with our results as shown in Fig. 3. During the stabilization step (Fig. 3 (b)), hydrolysis of $\mathrm{MgCl}_{2}$ is enacted by heat treatment around $458 \sim 513 \mathrm{~K} . \mathrm{Cl}$ produced $\mathrm{HCl}$ and then removed from electrospun fiber as a gas state [15].

$$
\mathrm{MgCl}_{2(\mathrm{~s})}+\mathrm{H}_{2} \mathrm{O}_{(\mathrm{v})}=\mathrm{MgOHCl}_{(\mathrm{s})}+\mathrm{HCl}_{(\mathrm{g})}
$$

At the elevated temperature for carbonization step, remained $\mathrm{MgOHCl}$ in electrospun fiber is decomposed to $\mathrm{MgO}$ and $\mathrm{HCl}[16]$.

$$
\mathrm{MgOHCl}_{(\mathrm{s})}=\mathrm{MgO}_{(\mathrm{s})}+\mathrm{HCl}_{(\mathrm{g})}
$$

The decomposition temperature of $\mathrm{MgOHCl}$ is calculated to be $828 \mathrm{~K}$ [17]. As we can see (c) in this Fig. 3, the $\mathrm{MgOHCl}$ mostly decomposed to $\mathrm{MgO}$. The characteristic peaks of $\mathrm{MgOHCl}$ at Bragg angles ( 2 theta) of roughly 15,32 , and 55 degrees diminished after carbonization and eventually completely 


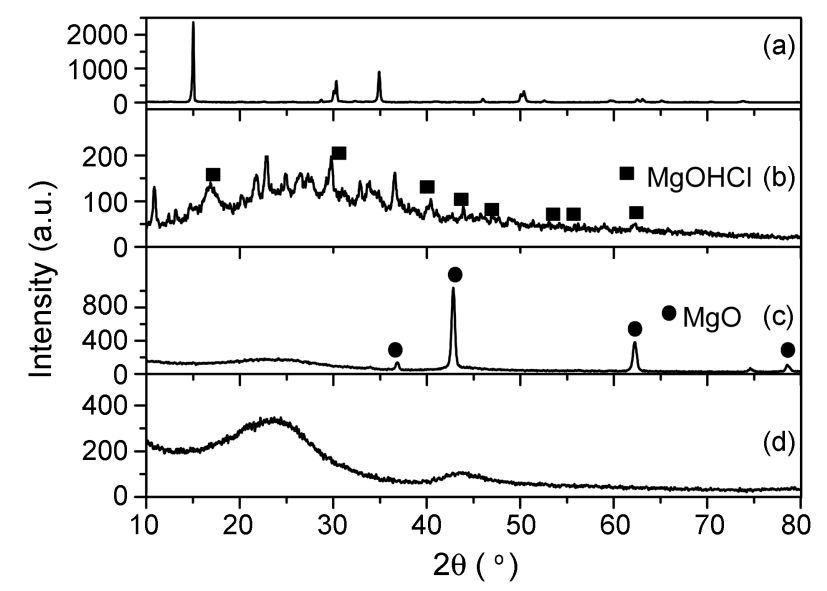

Fig. 3. XRD patterns: (a) pure $\mathrm{MgCl}_{2}$; (b) stabilized electrospun fiber (EM2); (c) carbonized electrospun carbon fiber (EM2) and (d) electrospun carbon fiber (EM2) after dissolving out $\mathrm{MgO}$ using $1 \mathrm{~mol} \mathrm{H}_{2} \mathrm{SO}_{4}$.

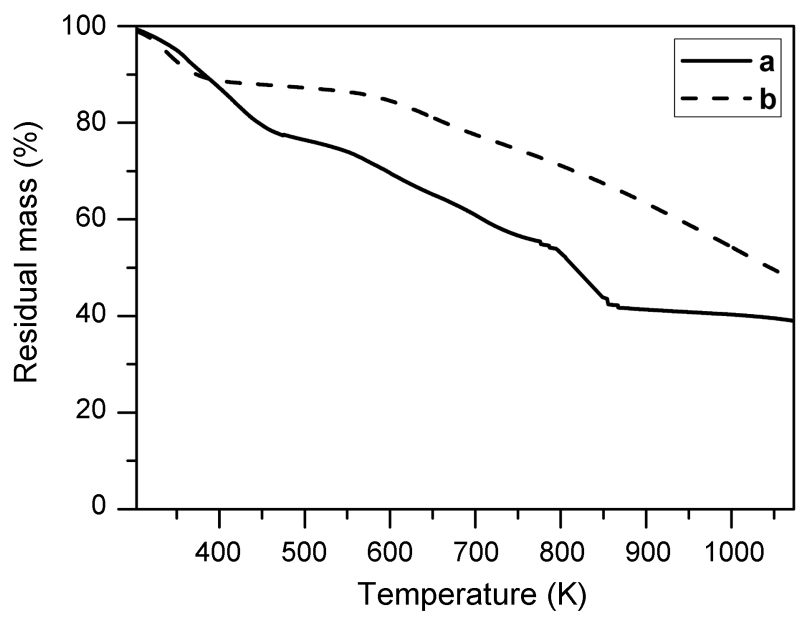

Fig. 4. Thermogravimetric curves of (a) stabilized electrospun fiber with $\mathrm{MgCl}_{2}$ (EM2) and (b) stabilized electrospun PAN fiber.

disappeared when it was dissolved out by using $\mathrm{H}_{2} \mathrm{SO}_{4}$.

Thermal gravimetric analysis (TGA) was used to study the decomposition of $\mathrm{MgOHCl}$. Fig. 4 is thermogravimetric curves of stabilized electrospun fiber prepared from $\mathrm{MgCl}_{2} / \mathrm{PAN}(2 / 3)$ solution ((a); EM2) and stabilized electrospun PAN fiber ((b); without $\mathrm{MgCl}_{2}$ ). Serious weight loss of the samples EM2 is observed at around $823 \mathrm{~K}$ in TGA results, even though the weight of stabilized electrospun PAN fiber (b) decreased linearly with the temperature. This weight loss caused by decomposition of $\mathrm{MgOHCl}$, which occurred around this temperature due to the change from $\mathrm{MgOHCl}$ to $\mathrm{MgO}$. This is also supported by XRD results shown in Fig. 3 as mentioned earlier.

Fig. 5, 6 and Table 1 show the textual properties of porous electrospun carbon fiber prepared. $\mathrm{MgO}$ in electrospun carbon fiber was dissolved out completely by using $\mathrm{H}_{2} \mathrm{SO}_{4}$ $(1 \mathrm{~mol} / \mathrm{L})$ and ended up pores in the carbon fiber. The surface area of electrospun fiber increased dramatically, as

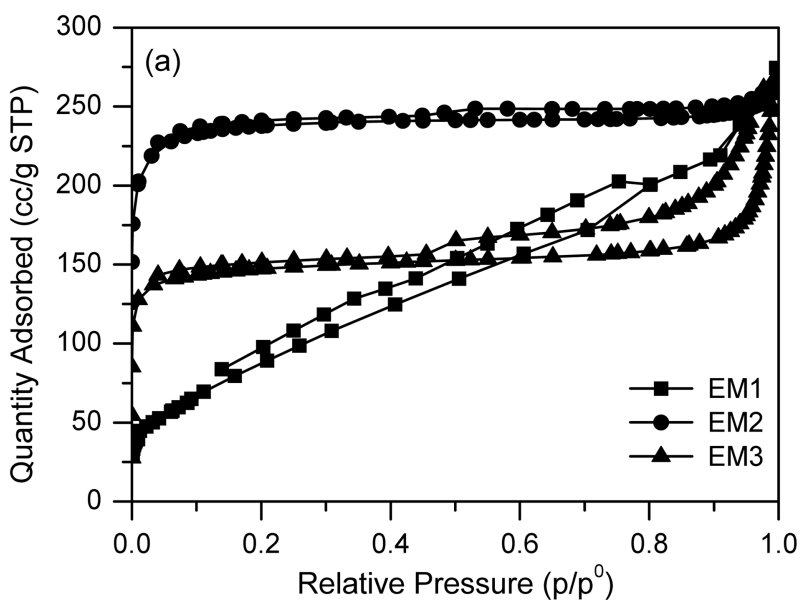

Fig. 5. Nitrogen adsorption-desorption isotherms various mixing ratios in $\mathrm{MgCl}_{2} / \mathrm{PAN}$.

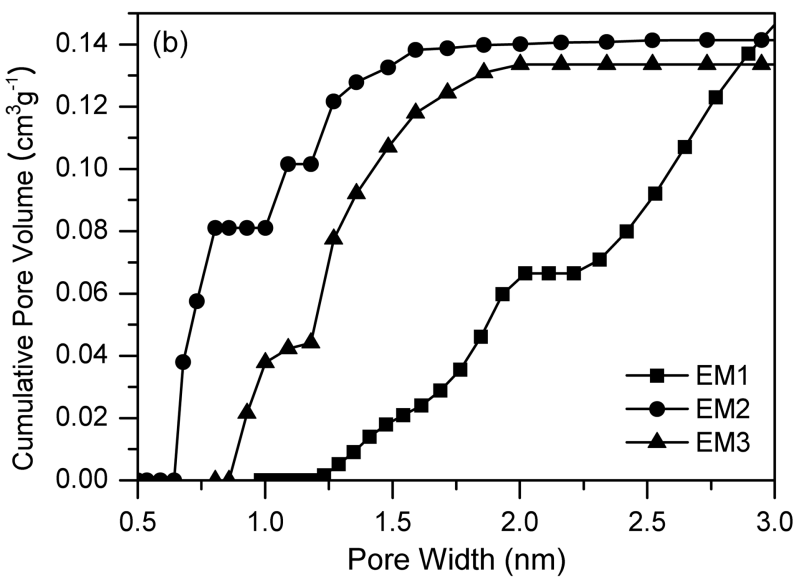

Fig. 6. DFT pore size cumulative volume various mixing ratios in $\mathrm{MgCl}_{2} / \mathrm{PAN}$.

the weight ratio of $\mathrm{MgCl}_{2} / \mathrm{PAN}$ increased. It is believed that weight ratio of $\mathrm{MgCl}_{2} / \mathrm{PAN}$ determines specific surface area and pore structure. According to the adsorption isotherm by IUPAC classification [18], the sample EM1 is showing Type II, whereas the other samples are showing Type I. It is shown that carbon fiber has almost mesopores, when weight ratio of $\mathrm{MgCl}_{2} / \mathrm{PAN}$ is $1 / 3$. Whereas on the other weight ratios of $\mathrm{MgCl}_{2} / \mathrm{PAN}$ is $2 / 3$ and $3 / 3$, dissolving out $\mathrm{MgO}$ decomposed from $\mathrm{MgCl}_{2}$ mainly create micropore on electrospun carbon fiber surface. Both EM2 and EM3 samples have the steep change of isotherm curves in low relative pressure (less than 0.01 bar), showing they have the developed micropore structure [19]. They also have the slow change of isotherm curves over 0.1 of relative pressure, indicating the mesopore also was developed through dissolving $\mathrm{MgO}$.

Fig. 7 shows the hydrogen adsorption capacity with changes of the weight ratio of $\mathrm{MgCl}_{2} / \mathrm{PAN}$. It is observed that hydrogen adsorption capacity is a linear function of pressure. As the specific surface area and micropore volume increase, 
Table 1. Pore Parameters Determined by BET and t-plot on the Electrospun Carbon Fiber

\begin{tabular}{ccccc}
\hline $\begin{array}{c}\text { Weight ratio of } \\
\mathrm{MgCl}_{2} / \mathrm{PAN}\end{array}$ & $\begin{array}{c}\left.\mathrm{S}_{\mathrm{BET}}{ }^{\mathrm{l}}\right) \\
\left(\mathrm{m}^{2} / \mathrm{g}\right)\end{array}$ & $\begin{array}{c}\mathrm{V}_{\mathrm{T}}{ }^{2)} \\
\left(\mathrm{cm}^{3} / \mathrm{g}\right)\end{array}$ & $\begin{array}{c}\mathrm{V}_{\mathrm{M}}{ }^{3)} \\
\left(\mathrm{cm}^{3} / \mathrm{g}\right)\end{array}$ & $\mathrm{V}_{\mathrm{M}} / \mathrm{V}_{\mathrm{T}}$ \\
\hline $1 / 3$ (EM1) & 346.8 & 0.4 & 0.02 & 0.05 \\
$2 / 3$ (EM2) & 799.8 & 0.4 & 0.32 & 0.8 \\
$3 / 3$ (EM3) & 493.9 & 0.36 & 0.19 & 0.52 \\
\hline
\end{tabular}

${ }^{11} \mathrm{~S}_{\mathrm{BET}}$ : BET specific surface area, ${ }^{2)} \mathrm{V}_{\mathrm{T}}$ : Total pore volume, ${ }^{3)} \mathrm{V}_{\mathrm{M}}$ : t-plot micro pore volume

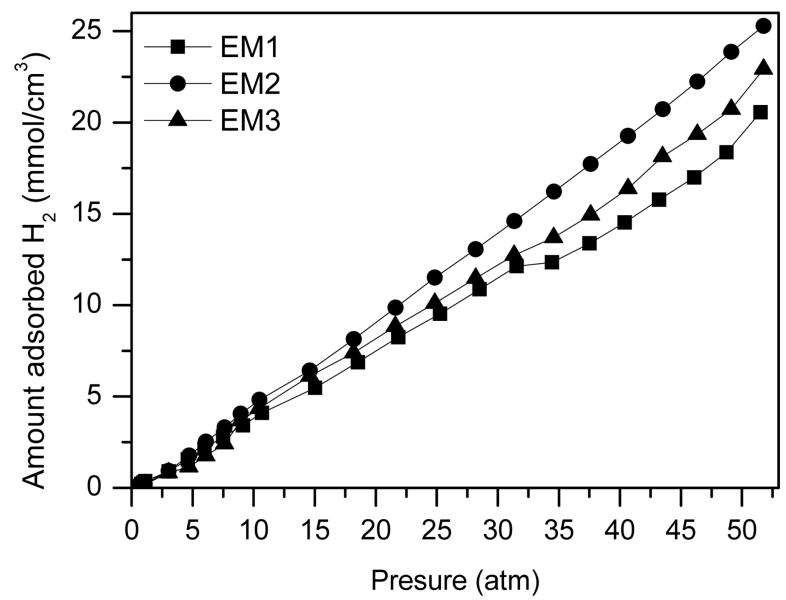

Fig. 7. $\mathrm{H}_{2}$ adsorption isotherms of various mixing ratios in $\mathrm{MgCl}_{2} / \mathrm{PAN}$.

the hydrogen adsorption of the materials also increases. This result indicates that hydrogen adsorption capacity is positively related to the pore volume in the range of micropore $[3,20]$. Eventually, the use of electrospinning method from PAN and $\mathrm{MgCl}_{2}$ as the precursor of $\mathrm{MgO}$ can be surely one of the way to apply for the hydrogen storage.

\section{Conclusions}

Porous electrospun carbon fibers were prepared by using $\mathrm{PAN} / \mathrm{MgCl}_{2}$ mixture solution with various weight ratios. Average diameter of porous electrospun carbon fibers increased from 1.3 to $3 \mu \mathrm{m}$ with increasing the amount of $\mathrm{MgCl}_{2}$ added. During the stabilization step, $\mathrm{MgCl}_{2}$ was hydrolyzed to $\mathrm{MgOHCl}$ by heat treatment. This $\mathrm{MgOHCl}$ was decomposed to $\mathrm{MgO}$ at elevated temperature of $823 \mathrm{~K}$ for carbonization step. Specific surface area and pore structure of prepared electrospun carbon fiber were decided by weight ratio of $\mathrm{MgOHCl} / \mathrm{PAN}$. When weight ratio of $\mathrm{MgCl}_{2} / \mathrm{PAN}$ is $1 / 3$, carbon fiber has almost mesopore. While on the other weight ratios of $\mathrm{MgCl}_{2} / \mathrm{PAN}$ are $2 / 3$ and $3 / 3$, carbon fibers have micropores. It is surely suggested that these developed pore structure developed from removing $\mathrm{MgO}$ electrospun fiber. The amount of hydrogen storage increased with increase of specific surface area and micropore volume of prepared electrospun carbon fibers. Therefore, this preparation method is expected to be prepared porous materials that it can adsorb hydrogen gas.

\section{Acknowledgement}

The authors gratefully acknowledge the 21C Hydrogen Frontier R\&D Program of the Ministry of Education, Science and Technology of Korea.

\section{References}

[1] Derbyshire, F.; Jagtoyen, M.; Thwaiter, M. "Activated carbons - production and application, in porosity in carbons", ed. J. W. Patrick, Edward Arnold, 1995.

[2] László, K.; Bóta, A.; Nagy, L. G. Carbon 2000, 38, 1965.

[3] Im, J. S.; Park, S. J.; Kim, T. J.; Kim, Y. H.; Lee, Y. S. J. Colloid Interf. Sci. 2008, 318, 42.

[4] Illán-Gómez, M. J.; García-García, A.; Salinas-Martínez de Lecea, C.; Linares-Solano, A. Energy Fuels 1996, 10, 1108.

[5] Lozano-Castelló, D.; Lillo-Ródenas, M. A.; Cazorla-Amorós, D.; Linares-Solano, A. Carbon 2001, 39, 741.

[6] Lillo-Ródenas, M. A.; Lozano-Castelló, D.; Cazorla-Amorós, D.; Linares-Solano, A. Carbon 2001, 39, 751.

[7] Raymundo-Piñero, E.; Cazorla-Amorós, D.; Linares-Solano, A.; Delpeux, S.; Frackowiak, E.; Szostak, K.; Béguin, F. Carbon 2002, 40, 1614.

[8] Maciá-Agulló, J. A.; Moore, B. C.; Cazorla-Amorós, D.; Linares-Solano, A. Carbon 2004, 42, 1367.

[9] Kyotani, T. "Porous carbons", ed. E. Yasuda, M. Inagaki, K. Kaneko, M. Endo, A. Oya, Y. Tanabe, Carbon alloys, Amsterdam: Elsevier, 2003, 109.

[10] Shi, Z. G; Feng, Y. Q.; Xu, L; Da, S. L. Carbon 2003, 41, 2668.

[11] Fuertes, A. B.; Pico, F.; Rojo, J. M. J. Mater. Sci. 2002, 137, 907.

[12] Inagaki, M.; Miura, H.; Konno, H. J. Eur. Ceram. Soc. 1998, 18, 1011.

[13] Inagaki, M.; Kobayashi, S.; Kojin, F.; Tanaka, N.; Morishita, T.; Tryba, B. Carbon 2004, 42, 3153.

[14] Morishita, T.; Soneda, Y.; Tsumura, T.; Inagaki, M. Carbon 2006, 44, 2360.

[15] Shand, M. A. "The Chemistry and Technology of Magnesia", John Wiley \& Sons, New York, 2006, 59.

[16] Kipourosa G. J.; Sadoway D. R. J. Light Metals 2001, 1, 111.

[17] Kipouros, J.; Sadoway, D. R. "The chemistry and electrochemistry of magnesium production", vol. 6, ed G Mamantov, C. B. Mamantov, J. Braunstein, Advances in Molten Salt Chemistry, Elsevier, Amsterdam, 1987, 127.

[18] Sing, K. S. W.; Everett, D. H.; Haul, R. A. W.; Moscou, L.; Pierotti, R. A. Pure Appl. Chem. 1985, 57, 603.

[19] Im, J. S.; Park, S. J.; Lee, Y. S. J. Colloid Interf. Sci. 2007, $314,32$.

[20] Jin, H. K.; Lee, Y. S.; Hong, I. P. Catalysis Today 2007, 120, 399. 